\title{
MONSTROS DE BRINQUEDO: O DESIGN E A INFÂNCIA CONTEMPORÂNEA
}

Michelle Cotrim

Universidade do Estado de Minas Gerais

michellecotrim@hotmail.com

Rita A. C. Ribeiro

Universidade do Estado de Minas Gerais

rribeiroed@gmail.com

Resumo: O presente artigo tem como objetivo investigar a relação entre design e infância no cenário contemporâneo a partir do olhar sobre os brinquedos que trazem em sua essência a temática monstro. $O$ artigo é dividido em quatro partes e apresenta, através de análises e revisão bibliográfica, as mudanças nos aspectos estéticos e culturais, abordando elementos relativos ao comportamento coletivo e social conjugando com o discurso sobre a alegoria contemporânea do zumbi, a virtualização da vida, o monstro como metáfora, o dissolver dos limites entre o bom e o mau, o encurtamento e prolongamento da infância e o gótico contemporâneo. Como objetos de estudo foram utilizados as pelúcias interativas Furbys, a linha Marvel Super Hero Mashers e as bonecas Monster High.

Palavras-chave: Design, Infância, Monstros

Abstract: This article aims to investigate the relationship between design and childhood in the contemporary scene based on toys that bring in their essence the monster thematic. The article is divided into four parts and shows, through analyses and literature review, the changes in aesthetic and cultural aspects, addressing details of the collective and social behaviour combining with the discourse on zombie contemporary allegory, life virtualization, the monster as metaphor, the dissolution of boundaries between the good and the bad, the shortening and lengthening of childhood and contemporary Gothic. As empirical objects were used Furby, Marvel Super Hero Mashers and Monster High dolls.

Keywords: Design, childhood and monsters. 


\section{INTRODUÇÃO}

É sabido que, desde muito tempo, os chamados monstros povoam o imaginário infantil, através dos mitos, lendas, cantigas e contos de fadas. Inicialmente estes seres fantásticos eram entendidos como o elemento maligno, do qual era necessário distância e que suscitava medo e terror.

Hood (2008), ao abordar o gênero de horror para crianças através do viés literário, pontua que este servia ao propósito didático, como por exemplo a figura dos monstros nos contos de fadas. Os seres fantásticos que povoam estas estórias, se tornam responsáveis por criar fronteiras entre o certo e errado, o bom e o mau - o Lobo delimita o que é seguro e o que é perigoso no conto de Chapeuzinho Vermelho.

Porém, pode-se verificar que a maneira como os monstros são construídos na contemporaneidade e, consequentemente, recebidos pela sociedade tem se alterado. Nota-se que estes deixaram de ser percebidos somente como a representação do mal e passaram a ser entendidos também como parte integrante, aceitável e humanizada, por vezes um amigo. $\mathrm{O}$ afastamento da imagem maléfica que esses seres fantásticos carregavam proporcionou que gradativamente adquirissem uma nova configuração. Percebemos que, esta nova configuração foi absorvida pela cultura pop infantil e incorporada ao design de brinquedos.

\section{PLUSH TOYS: ENTRE URSOS E MONSTROS}

Um dos primeiros plush toy (bicho de pelúcia) a ser comercializado foi o Teddy Bear em 1903. Segundo Kline, a criação deste urso de pelúcia possibilitou "uma reformulação do pensamento público sobre a socialização e brincadeiras para crianças que se estende ininterrupta em nossa era [...] que transformaram os animais de pelúcia na iconografia da inocência emocional." (KLINE,1995, p.150, tradução nossa)

Observa-se que a partir da década de 1960 verifica-se a crescente presença dos Teddys nas mídias televisivas por meio de séries e animações, e a proliferação de personagens e brinquedos inspirados nestes a partir dos anos 1980, como por exemplo: Ursinhos Carinhosos em 1983, The Adventures of Teddy Ruxpin em 1986, entre outros.

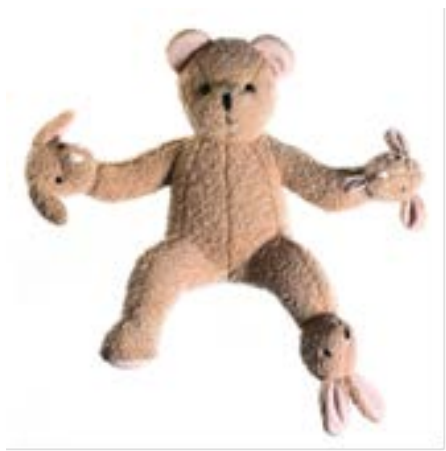

Figura 1 - "Figura 1 - Teddy Bear Band"

Fonte: www.starck.com

Em 1998, o designer Philippe Stark lançou sua versão para o ursinho de pelúcia, o Teddy Bear Band. Segundo Stark, a intenção era prolongar a vida útil do brinquedo, uma vez que caso a criança enjoasse do urso, poderia simplesmente virar o corpo da pelúcia e então brincar com o coelho. No entanto o aspecto final do produto (Figura 1), 
um ursinho meio Frankenstein, não obteve grande sucesso e foi considerado por alguns como controverso.

Também em 1998 as lojas de brinquedos foram invadidas por monstrinhos interativos de pelúcia, o Furby, um bicho de pelúcia que apresentava a possibilidade de interação com a criança devido às interfaces de inteligência artificial.

Criação dos designers de brinquedos norte-americanos Dave Hampton e Richard C. Levy, a ideia para o Furby surgiu como resposta ao Tamagotchi (Figura 2). Com base no conceito de pet artificial, Dave decidiu criar uma versão, na qual a criança pudesse ter uma maior interação mimetizando a experiência do cuidado com um bicho de estimação real. Depois de aproximadamente dezoito meses, surgia à primeira geração de Furbys.

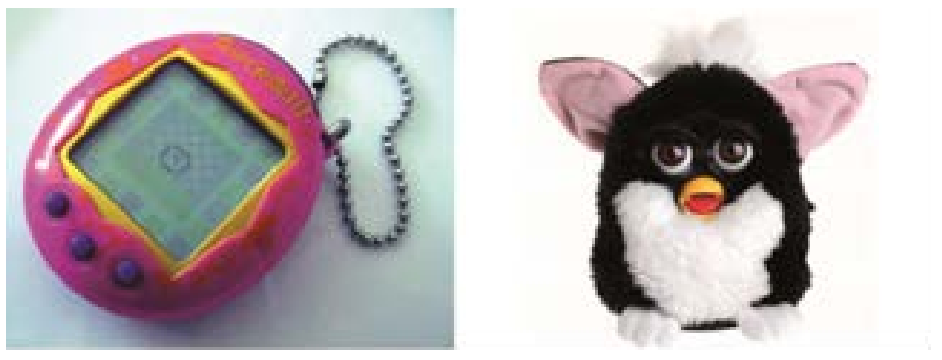

Figura 2 - "Figura 2 - Tamagotchi x Furby"

Fonte: Elaborada pela autora

Devido sua natureza híbrida, meio robô, meio pelúcia, os Furbys podem ser considerados figuras monstruosas, pois de acordo com Cohen (1993), o hibridismo é uma das características definidoras dos monstros.

Os Furbys são considerados brinquedos inteligentes, pois possuem dispositivos de reconhecimento de voz, processamento e armazenamento de dados entre outros. Segundo Vecchio estas criaturas "poderiam interagir com a criança bem como com outros Furbys [...] Eles poderiam cantar, dançar, tagarelar, espirrar, dar risada, falar mais de oitocentas frases, piscar os olhos e responder de uma forma ou de outra ao toque da criança." (VECCHIO, 2003, p. 89, tradução nossa). Desta forma os Furbys proporcionariam uma relação entre a criança e o pet mais próxima da realidade do que os Tamagotchis.

Ao ligar o Furby pela primeira vez, esse passa imediatamente a comunicar-se e a interagir com seu derredor, inicialmente em seu idioma oficial o furbish, amalgama de diversas línguas tais como hebraico e mandarim, e desenvolvido também por Dave. Posteriormente, a partir da interação com o ambiente externo, o Furby apresenta uma ilusão de aprendizado, ao expandir seu discurso incluindo palavras pré-armazenadas no idioma do seu proprietário.

Após o sucesso inicial, houve um decrescimento nas vendas dos Furbys e apesar dos lançamentos contínuos de novas gerações, a linha entrou em hiato em 2007. É importante ressaltar que em 2005, foi criado o Emoto-Tronic Furby, que possuía uma gama maior de emoções, reações e movimentos e em contraste as primeiras criaturas possuíam um botão de liga/desliga.

Em 2012, chegou ao mercado, o Furby Boom, de aparência semelhante ao de 1998, porém com orelhas plásticas, olhos em LED e uma roupagem em cores vibrantes e padrões geométricos e novamente sem um botão de liga/desliga. 
A principal novidade no Furby Boom é que ele possui 'personalidades' que podem se alterar. De acordo com Neustein e Markowitz (2013), o Furby Boom é "imbuído de uma série de comportamentos sociais. [...] um Furby contém um conjunto de personalidades embutidas que evolui para refletir como têm sido tratados."(NEUSTEIN; MARKOWITZ, 2013, p.16, tradução nossa) Se bem cuidado, um Furby pode tornar-se afável, porém se mal tratado ou negligenciado pode tornar-se rude.

Outro ponto interessante é a possibilidade de interação com o meio digital, por meio de uma série de aplicativos, que incluem como opções dar banho, tirar um 'raio$X$ ' de seu animal e até mesmo 'chocar' um Furbling - uma espécie de filhote de Furby que existe tanto no meio digital quanto no meio físico.

Com base nos apontamentos acima nota-se um padrão entre os Teddys, os Tamagotchis e os Furbys. Vecchio aponta que o conceito destes brinquedos é o mesmo, promover o sentimento de cuidado. (VECCHIO,2003)

Sendo assim pode-se entender que assim como o primeiro Teddy Bear promoveu uma conexão emocional entre as crianças e os brinquedos, os Furbys também o fazem, entretanto observa-se que neste caso há a associação entre a emoção e a inteligência artificial na busca de se promover uma relação simulacro entre a criança e o pet artificial.

Paradoxalmente ao estímulo buscado pelo Furby, de cuidado e carinho, em 2012 foi lançado a linha de pelúcias interativas Smasha - Ballz, criaturas que respondem aos estímulos externos através da emissão de sons e vibração. A ideia principal da brincadeira é que ao serem sacudidos e/ou arremessados contra o piso os monstrinhos emitem sons e vibram, quanto mais forte o golpe mais alto o som é emitido.

Ao transformarmos o monstro em algo fofinho, digno de ser amado, nos aproximamos ao conceito argumentado por Maja Brzozowska-Brywczyńska. Em seu artigo, Monstrous/Cute. Notes on the ambivalent nature of Cuteness, a autora argumenta sobre as implicações da associação entre o monstro e o 'fofo'. De acordo com a mesma "conforme a definição do senso comum, fofo e monstruoso parecem habitar reinos distantes e mutuamente exclusivos. [...] Separamos cuidadosamente o monstro do fofo e a própria noção de rastrear semelhanças entre os dois parece altamente imprópria."(BRZOZOWSKA-BREYWCZYNSKA, 2007, p.213, tradução nossa)

Porém a própria Brzozowska-Brywczyńska, afirma que tanto o fofo quanto o monstruoso são pertencentes ao reino do que é estranho. A autora prossegue discutindo que "a natureza 'esquizofrênica' do fofo permite que esse seja usado como uma camada de revestimento adocicada para ideias e comportamentos que ultrapassam as regras sociais, entrando no campo do que é proibido." (BRZOZOWSKABREYWCZYNSKA, 2007,p.219, tradução nossa)

Com base nessa proposição pode-se adotar como exemplo o Smasha-Ballz, que com seu exterior fofinho encoraja as crianças a um comportamento violento e cruel incentivo a agressão como diversão. Segundo Maja:

A ambivalência é a palavra que torna possível posicionar fofo e monstruoso em uma mesma dimensão, espaço denominado por Michel Foucault de heterotopia, o lugar fora da norma, o site do potencial revolucionário para mudar, para constituir uma ordem alternativa, onde a coerência entre palavras e a realidade não é mais possível, onde o paradoxo é a regra de 
Portanto compreende-se que brinquedos como: Furby, Smasha-Ballz, entre tantos outros favorecem para a reformulação da ordem vigente, dando origem a uma 'nova' ordem.

\section{MADRUGADA DOS MORTOS VIVOS}

A figura do Zumbi, de acordo com a maioria dos pesquisadores, originou-se na região da África Ocidental e acompanhou os descendentes desta região ao redor do mundo. Um dos lugares nos quais esses se estabeleceram foi o Haiti e como consequência da ocupação americana (de 1915 a 1934) neste país, o mito zumbi foi introduzido na cultura popular global.

Boluk e Lenz (2011) dividem a genealogia dos zumbis em três: a tradição haitiana, os mortos-vivos do filme de George A. Romero, A Noite dos Mortos Vivos, de 1968 e o zumbi contemporâneo, uma espécie que se apresenta como uma doença. Observa-se que inicialmente empregada na cultura pop juvenil e adulta, o zumbi ganhou o mundo e passou a figurar filmes, quadrinhos, games, adquirindo cada vez mais espaço entre adolescentes e crianças.

Griffin (2012) aponta como exemplos "títulos ensanguentados, como a série de jogos Resident Evil, bem como uma infinidade de outros, incluindo Dead Rising, House of the Dead, Left 4 Dead, e até mesmo Plants vs. Zombies." (GRIFFIN, 2012, tradução nossa)

É interessante notar que no caso de Plants vs Zombies há uma transposição do meio digital para o meio físico através da criação da linha de brinquedos de mesmo nome. A linha é composta por plush toys, figuras de ação, quebra-cabeças, entre outros e tem como público-alvo de toddlers (crianças de 0- 3 anos) à adultos.

Leverette e McIntosh (2008) ao argumentarem sobre a cultura zumbi, colocam que: "a popularidade dos zumbis em videogames pode em parte ser dada pela maneira que eles articulam, em um contexto de fantasia mediada, os medos culturais contemporâneos da perda de autonomia ou a capacidade da ciência para criar uma devastação apocalíptica." (LEVERETTE; MCINTOSH, 2008, p.153, tradução nossa)

Christie e Lauro (2011) sugerem que "o zumbi encarna 'nosso medo de perda da identidade', tanto quanto o apocalipse zumbi global continua a servir como ponto crucial para o heroísmo e campo de teste para os valores humanos" (CHRISTIE; LAURO, 2011, p.160, tradução nossa) Leverette e McIntosh acrescentam que os "jogos de zumbis provêm o inimigo ideal: eles são fortes, implacáveis, e já estão mortos; eles têm uma aparência espetacularmente horrível; e convidam o jogador para explodi-los sem pensar duas vezes e sem culpa." (LEVERETTE; MCINTOSH, 2008, p.153, tradução nossa).

Outro brinquedo que tem o zumbi como elemento principal é o Balança Zumbi (Figura 3), um jogo em forma de quebra-cabeça tridimensional com marcação de tempo. Composto por um base fixa, incluindo o corpo do zumbi, o objetivo é montar as peças faltantes (olhos, braço, cérebro, etc) antes que o tempo acabe, caso a tarefa não seja completada o zumbi 'explode', dando início a uma nova tentativa.

Chtistie e Lauro argumentam que "um zumbi é como uma pessoa idosa, e como uma criança, dessa forma é limitado a um pequena parcela de necessidades egoístas e o panorama imediato que o cerca." (CHRISTIE; LAURO, 2011, p.184, tradução nossa) As autoras seguem pontuando que "os zumbis sugerem uma psique mais simples, mais livre, e biologicamente mais sintonizada - uma tão reduzida aos impulsos evolutivos 
primordiais [...]. Para o zumbi, as escolhas são fáceis e o mundo é descomplicado." (CHRISTIE; LAURO, 2011, p.186, tradução nossa).

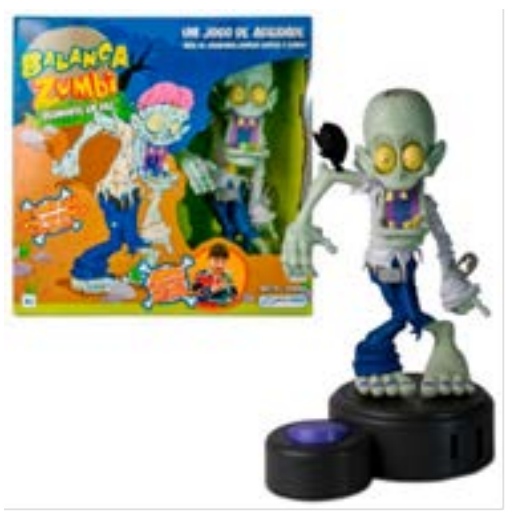

Figura 3 - "Figura 3 - Blança Zumbi"

Fonte: www.casabellapresentes.com.br, 2016.

Talvez a figura do zumbi na contemporaneidade, se apresente como uma válvula de escape, uma versão mais simplificada do cotidiano complexo, ao mesmo tempo em que dialoga com o hibridismo próprio do momento atual, ao ponto que se trata de um ser nem vivo nem morto, mas em um estado suspenso, governado por instintos primitivos e que carrega em sua aparência decadente a presença da morte.

Paffenroth aponta que "os filmes de zumbi [...] parecem por sua própria natureza oferecem uma crítica social e um olhar crítico moralizador sobre os seres humanos" (PAFFENROTH, 2006, p.134, tradução nossa), e com base nos apontamentos acima compreendemos que a figura do zumbi atual, expressa em filmes, seriados, games e brinquedos, pode ser entendida como uma alegoria da sociedade contemporânea, mais especificamente da Geração Z.

A Geração Z, composta por indivíduos que nasceram entre 1995 e 2005, que mais que nativos digitais têm em seu 'DNA' a tecnologia. Koulopoulos e Keldsen argumentam que:

Para a Geração Z, tecnologia é invisível; é apenas parte de como o mundo se comporta em direção a uma interação com ela. Os indivíduos dessa geração são cegos para a distinção entre a tecnologia e o comportamento natural de certos objetos. Para eles, tecnologia é apenas mais um fio no tecido de suas vidas. (KOULOPOULOS; KELDSEN, 2014, tradução nossa).

Os autores argumentam também que, a Geração $Z$ pode ser compreendida em um aspecto ampliado, o Efeito Geração Z, no qual a geração não é mais definida pela idade dos indivíduos que a compõem, mas pela escolha consciente na adoção por comportamentos típicos dessa geração, que passa a ser compreendida como um fenômeno social. Segundo Koulopoulos e Keldsen: "as características definidoras de uma geração - tecnologias distintas, modos de trabalho, e uma inabilidade de adaptação a novas ideias e experiências - não se aplicam mais. As ferramentas que utilizamos para viver, trabalhar e como entretenimento, agora, são praticamente idênticas. (KOULOPOULOS; KELDSEN, 2014, tradução nossa).

Entende-se portanto que o Efeito Geração $Z$ reduz as diferenças entre as gerações. Sabe-se que nos últimos cinquenta anos, no mesmo espaço/tempo, 
convivem de três a quatro gerações diferentes, porém adaptadas à realidade contemporânea. Como por exemplo avós, pais e netos compartilhando redes sociais, tutoriais no Youtube, blogs de moda, entre outros.

Dessa forma pode-se criar um paralelo entre o Efeito Geração Z e os filmes de zumbi da atualidade, tais como a série Resident Evil, Zombieland, Guerra Mundial Z e Warm Bodies. Nesses filmes a humanidade enfrenta um Apocalipse Zumbi, no qual o zumbi é considerado uma patologia, uma doença causada pela ciência que não respeita delimitações cronológicas transformando os indivíduos por onde passa em mortos vivos.

Da mesma forma o Efeito Geração Z, através da tecnologia, têm achatado as diferenças entre as faixas etárias, sem respeitar as variações e os comportamentos sociais típicos de cada uma, transformando a sociedade em uma horda de zumbis tecnológicos que aos poucos têm se tornado cada vez mais desconectada do mundo físico e mais dependente dos meios digitais.

\section{VIRA-MONSTRO, VIRA HERÓI: MARVEL SUPER HERO MASHERS}

Cohen coloca que os monstros são criados "através de um processo de fragmentação e recombinação em que elementos são extraídos 'de várias formas' [...] e então disposto como o monstro". (COHEN, 1993, p.11, tradução nossa) Em concordância a este argumento, Levina e Bui pontuam que, o monstro "pode ser [...] uma figura composta de organismos heterogêneos que são inseridos uns nos outros em um enxerto, esta hibridação, esta composição que coloca corpos heterogêneos em um conjunto pode ser chamado de monstro" (LEVINA; BUI, 2013, p. 22, tradução nossa) Com base nessas proposições entende-se que o brinquedo Marvel Super Hero Mashers, pode ser considerado como monstruoso.

A linha Marvel Super Hero Mashers é formada por figuras de ação, de heróis e vilões, baseadas nas histórias em quadrinho e filmes da Marvel. Cada figura é articulada e composta por peças intercambiáveis (Figura 4), compatíveis entre si, permitindo inúmeras combinações, dando origem a personagens híbridos que buscam a "perfeição".

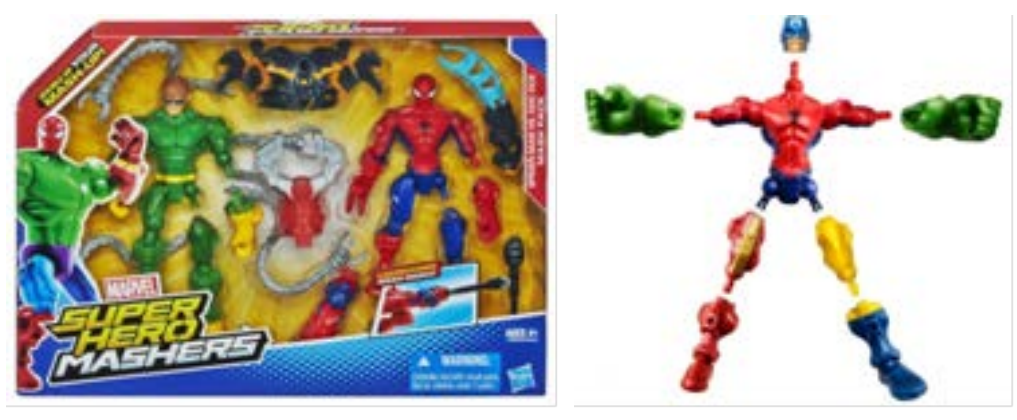

Figura 4 - "Marvel Super Hero Mashers"

Fonte: Elaborado pela autora, 2015.

O objetivo principal da brincadeira é a composição de um 'super-herói' que atenda a todos os pré-requisitos de quem o monta, sem defeitos ou pontos fracos, mesmo que para isso seja necessário agregar partes pertencentes a vilões.

Porém ao conjugar peças distintas em um único boneco, este deixa de ser completamente um herói, transformando-se em um ser sem uma categoria específica, 
assim como os monstros.

Outro ponto a ser ressaltado, é que a combinação de heróis e vilões em um único boneco pode ser entendida de forma semelhante a proposta por BrzozowskaBrywczyńska, no que diz respeito aos termos 'fofo' e monstro. Segundo a autora a associação de tais termos provoca a diluição dos conceitos de bom e mau transpondo este argumento para a discussão em questão pode-se inferir que um herói formado a partir de partes de um vilão pode vir a diluir as barreiras entre estes arquétipos e seus papéis como personagens.

Compreende-se ainda que a linha Marvel Super Hero Mashers pode ser entendida como um reflexo das questões referentes à identidade na contemporaneidade. Bauman (2001) sustenta que "num período abominavelmente curto de existência, [...] agora é oferecida a habilidade de espremer de si muitas vidas, uma série infinita de 'novos começos'". (BAUMAN, 2001, p.155).

Essa capacidade não é apenas uma possibilidade, é uma ordem imperativa de constante mudança de identidade, "outrora projeto vitalício, de limites coincidentes com a duração da vida, ele se transformou agora em atributo do momento. [...] é intermitente e sempre de novo montado e desmontado."(BAUMAN, 2001, p.180).

Bauman aponta também que:

O problema é escolher o melhor padrão entre os muitos atualmente em oferta, montar as partes do kit vendidas separadamente e apertá-las de uma forma que não seja nem muito frouxa [...] nem muito apertada (para que a colcha de retalhos não se desfaça de uma vez quando chegar a hora do desmantelamento, o que certamente acontecerá). (BAUMAN, 2001, p.13)

Halberstam (2000) aponta que a identidade contemporânea, assim como a identidade dos monstros, é fugaz, propensa a desconstrução e em contínuo processo de decomposição. Esta identidade se apresenta como uma espécie de identidade frankenstein, formada por diferentes partes não coesas costuradas entre si, um patchwork em eterno progresso, no qual o adquirir e o descartar têm igual valor e importância.

Desta forma pode-se argumentar que a criança ao brincar como Marvel Super Hero Mashers estaria se familiarizando com este conceito de identidade frankenstein híbrida e fragmentada. Ao montar, desmontar, misturar e recombinar as peças, a criança descobre que a identidade do herói, antes bem estabelecida, agora pode ser recombinada a partir de partes diversas, sejam essas provenientes de heróis e/ou vilões, em uma nova identidade dinâmica e pronta para ser reconstruída. Observamos que este conceito de identidade mutável tem sido aplicado em outros produtos tais como o Create a Monster da franquia Monster High.

\section{FRANKIE STEIN E OUTROS MONSTROS: A FRANQUIA MONSTER HIGH}

Frankenstein, talvez um dos monstros góticos mais famosos, surgiu no século XIX, no romance de terror de Mary Shelley intitulado Frankenstein: or the Modern Prometheus ${ }^{1}$.

Este ser monstruoso fruto híbrido das mãos humanas e da ciência, na obra

1 A primeira edição da obra foi lançada em 1818, com sucesso entre o público. No ano de 1831 a obra tem sua primeira edição popular em volume único. 
original é sempre referido como criatura (monstro) ou demônio, pois não possui um nome próprio. Após a adaptação para o cinema em 1931, passou a ser chamado de Frankenstein, sobrenome de seu criador na obra, Victor Frankenstein, e uma associação livre do público que percebe a criatura não apenas como criatura, mas possivelmente como um filho de Victor.

Comumente relacionado ao público adulto, Frankenstein gradativamente passou a despertar também o interesse das crianças, se popularizando através de séries televisivas, como Família Monstro. Aproveitando o sucesso das séries foram lançados vários brinquedos.

Lederer (2002) sugere que "na adaptação do monstro para consumo pelas crianças, o horror da criatura construída a partir de partes de corpos e tecido roubado de sepulturas foi de alguma forma silenciado, assim como seus atos criminosos." (LEDERER, 2002, p. 50, tradução nossa) Compreende-se então que ao ignorar os aspectos mais monstruosos da criatura, de certa forma houve a domesticação do personagem.

Dentro do universo de brinquedos contemporâneos um dos exemplos de maior sucesso da apropriação deste personagem é a boneca Frankie Stein da franquia Monster High, voltada para o público feminino de 08 a 12 anos.

Monster High é constituída por bonecos/personagens com inspiração em monstros, tem como pano de fundo o High School, equivalente ao ensino médio brasileiro. Atualmente a linha disponibiliza mais de cinquenta personagens, cada qual contém uma biografia constando interesses, peculiaridades (monster quirk) e outras informações.

Dentre os personagens há apenas uma figura adulta, Headless Headmistress Bloodgood, a diretora da escola que tem como base para seu personagem a figura do Cavaleiro Sem Cabeça. Assim como o personagem que a originou, Bloodgood, também anda na companhia inseparável de seu cavalo, nomeado Nightmare (versão original). o restante da linha é composto por adolescentes.

Schor aponta que "apesar dos esforços para sensibilizar os profissionais sobre o papel dos brinquedos na reprodução de estereótipos doentios de gênero, as maiores empresas fabricantes de brinquedos ainda seguem a política de segregação." (SCHOR, 2009, p.39) Entretanto observamos que Monster High, aos poucos tem buscado romper com esses limites. Dentre os personagens que desafiam as convenções sociais usuais podemos citar Garrott-Duroque, um adolescente que de acordo com sua biografia (disponibilizada no site) adora desenhar e criar roupas, atividades normalmente atribuídas (dentro do universo infantil) a personagens femininos e Kjesti Trollson, uma garota que se autointitula nerd e tem como atividade favorita jogar video games, uma prática comumente associada ao universo infantil masculino. A franquia também se diferencia por apresentar personagens das mais diversas origens culturais e monstruosas como em um convite a abraçar a diversidade e pluralidade.

A linha Monster High conta também com inúmeras referências ao contexto gótico, desde a origem de alguns dos monstrinhos até a estética do site em tons escuros, predominantemente o preto, passando pelo uso de elementos como caixões, caveiras, corte vampira.

Halberstam sugere que a cultura contemporânea está passando por uma gotificação, que não está presa somente a literatura ou ao cinema, mas diluída em todas as faixas etárias e em todos os espectros da cultura. A autora pontua ainda que: 
Com o gótico pós-moderno já não tentamos mais identificar o monstro e fixar os termos de sua deformidade, ao invés disso o gótico pós-moderno nos adverte para desconfiarmos dos caçadores de monstros, feitores de monstros, e acima de tudo, de discursos revestidos em pureza e inocência. O monstro sempre representa o rompimento das categorias, a destruição das fronteiras, e a presença de impurezas e por isso precisamos dos monstros e precisamos reconhecer e celebrar as nossas próprias monstruosidades. (HALBERSTAM, 2000, p.03, tradução nossa)

A linha Monster High parece entender e incorporar este conceito através do convite imperativo em seu lema: "seja você mesmo, seja único, seja um monstro".

Para o propósito do artigo foi selecionada para análise a personagem Frankie Stein, que compõem junto a Draculaura, Ghoulia Yelps, Cleo de Nile, Lagoona Blue e Clawdeen Wolf a tribo das Amigas Monstrinhas (Figura 5) conforme o site de Monster High. A análise procurou contemplar a complexidade da personagem através da exploração do conteúdo disponível nas diversas plataformas oferecidas pela linha: livros, web episódios, filmes, etc.
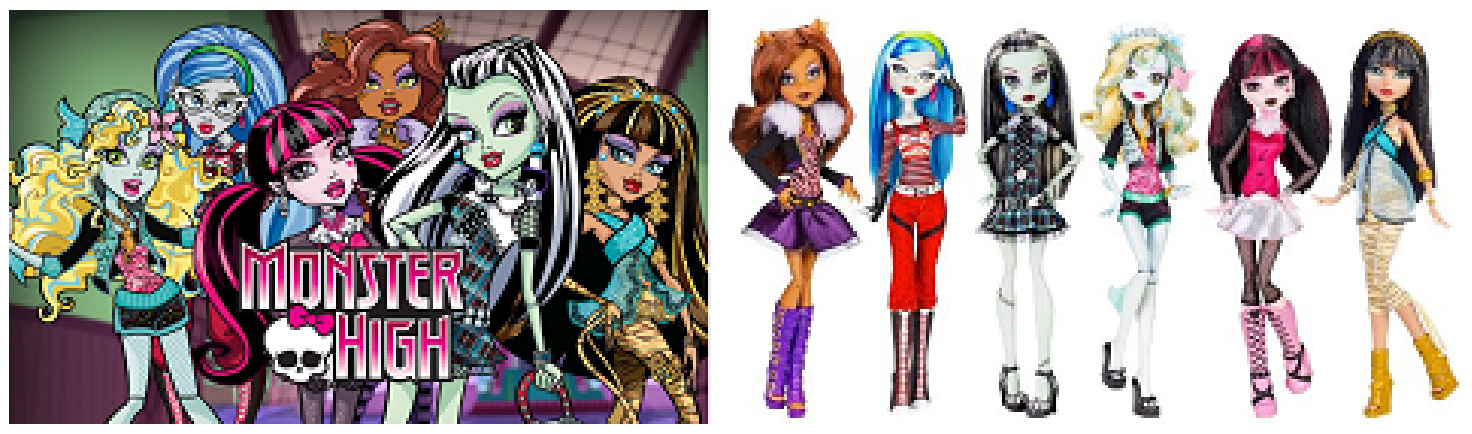

Figura 5 - "Amigas Monstrinhas Monster High, da esquerda para direita as bonecas Clawdeen Wolf, Ghoulia Yelps, Frankie Stein, Lagoona Blue, Draculaura e Cleo de Nile."

Fonte: Elaborada pela autora, 2015.

Frankie Stein, geralmente a narradora dos episódios da série, é filha de Viktor Stein e Viveka (baseados nos personagens Frankenstein e sua Noiva). Frankie nasceu com 15 anos de idade e, apesar de ter a inteligência e a capacidade física de uma adolescente, apresenta-se como uma personagem ligeiramente imatura (inocente), pois não tem a experiência de vida compatível com sua idade. Esta imaturidade pode indicar um reflexo do encurtamento da infância na contemporaneidade, processo encorajado pelos pais, mídia e tecnologia, pela cobrança acadêmica ou da indústria da moda. (ELKIND, 2001)

Outro aspecto que aproxima a personagem à infância contemporânea é a opção pela paternidade tardia de Viktor e Viveka. De acordo com o diário de Frankie, apesar do grande desejo em se tornarem pais, estes postergaram por cem anos a criação de Frankie, pois não se sentiam preparados para a paternidade. Da mesma forma que Viveka e Viktor, na contemporaneidade muitos pais adiam a paternidade em função de realizações profissionais, estabilidade financeira, entre outros. 


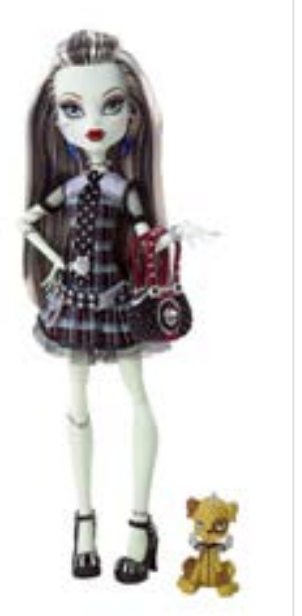

Figura 6 - "Frankie Stein"

Fonte: Elaborada pela autora, 2015.

Assim como o Frankenstein de Mary Shelley, Frankie (Figura 6) também é constituída por partes de corpos variados, um dos elementos que demonstra isto de forma sutil são os olhos de cores diferentes. Porém nos web-episódios à referência a "hereditariedade` monstruosa fica mais pungente, como em uma das cenas em que a personagem perde uma perna ao dar um salto acrobático. Outros elementos, tais como as costuras aparentes, os pinos no pescoço e pele levemente esverdeada a aproximam da imagem imortalizada por Boris Karloff no cinema; já o cabelo, uma mescla de preto e branco, lembra a figura da Noiva de Frankenstein, do filme homônimo de 1935.

\section{CONSIDERAÇÕES FINAIS}

O presente artigo buscou apresentar uma análise reflexiva a partir da associação entre monstros e brinquedos. Foi investigado a relação entre o design de brinquedos, a figura dos monstros, o conceito de infância e a cultura pop infantil.

A primeira seção explorou os brinquedos e jogos inspirados em zumbis, a partir dos quais foi desenvolvido um paralelo entre a relação dos mesmos, a contemporaneidade e a Geração Z.

O segundo segmento discutiu a união monstros e bichos de pelúcias - como por exemplo o Furby - e sua ligação com o conceito de monstro fofinho, proposto por Brzozowska-Brywczyńska.

A terceira parte averiguou a hibridização como aspecto determinante para o ser monstruoso, através da análise do brinquedo Marvel Super Hero Mashers e refletiu sobre questões relacionadas a identidade contemporânea (fragmentada e dinâmica).

A última seção examinou a linha Monster High e dialogou a respeito do uso da apropriação de inquietações contemporâneas às bonecas da linha e da utilização de elementos góticos pela cultura pop atual.

Com base na discussão proposta nos permitimos apontar que talvez não esteja ocorrendo apenas uma compressão da infância ou uma adultização das crianças, o que percebemos é uma espécie de achatamento das gerações esmagando as distinções.

O limite entre o que é próprio da criança e próprio do adulto está cada vez mais diluído, hoje é comum encontrar meninas de salto alto, e adultos com roupas juvenis em peças como bermudas, shorts, bonés entre outros. Tornamos-nos uma espécie 
hibrida, nem criança, nem adulto, e nos aproximamos da metáfora do monstro.

Cada dia que passa, observa-se que a mídia nos convida a abraçar nossa parte monstro, nosso lado estranho e nossas imperfeições em jogos e séries que trazem os zumbis como seres 'bestiais', porém livres e descomplicados; em brinquedos como Super Hero Mashers que encorajam a buscarmos o melhor, mesmo que isso provenha de um vilão e em bonecas monstrinhas que pregam a adolescência eterna.

\section{REFERÊNCIAS}

BAUMAN, Zigmund. Modernidade líquida. Rio de Janeiro: J.Zahar, 2001.

BOLUK,Stephanie ; LENZ,Wylie. Generation Zombie: Essays on the Living Dead in Modern Culture. North Caroline: McFarland, 2011.

BRZOWSKA-BRYWCZNSKA, Maja. Monstrous/Cute: Notes on the Ambivalent Nature of Cuteness. In: SCOTT, Niall (org.). Monsters and the Monstrous: Myths and Metaphors of Enduring Evil. Amsterdam: Rodopi B.V. 2007

CRISTIE, Deborah. LAURO, Sarah. Better Off Dead: The Evolution of the Zombie as Post-human. USA: Fordham, 2011.

COHEN, Jeffrey. (org.) . Monster Theory: Reading Cultures. Minneapolis. University of Minessota Press, Visible Evidence Series, 1996.

ELKIND, David. The Hurried Child: Growing Up Too Fast Too Soon. Cambridge: DaCapo, 2001.

GRIFFIN, Marcus. All about Zombies. Woodbury, Minnesota : Llewellyn Publications, 2012.

HALBERTSTAM, Jude. Skin Shows: Gothic and the Technology of Monsters. 3ed. Duke University Press. 2000

HIRSCHMANN, Kris. Frankenstein. San Diego: ReferencePoint, 2012.

HOOD, Katherine. On Beyond Boo! Horror Literature for Children. 2008. 244 f. Tese Indiana University of Pennsylvania, Doctor of Philosophy.

KLINE, Stephen. Out of the Garden: Toys and Children's Culture in the Age of TV Marketing. London: Verso, 1995.

KOULOPOULOS, Tom; KELDSEN, Dan. The Gen Z Effect: The Six Forces Shaping the Future of Business. Brookline: Bibliomotion,2014.

LEDERER, Susan. Frankenstein: Penetrating the Secrets of Nature. Picataway: Rutgers, 2002.

LEVINA, Marina; BUI, Diem-My. Monster Culture in the 21st Century: A Reader. London: Bloomsbury, 2013.

MCINTOSH,Shawn; LEVERETTE, Marc. Zombie Culture: Autopsies of the Living Dead. Maryland: Scarecrow, 2008.

NEUSTEIN, Amy; MARKOWITZ,Judith (org.) Mobile Speech and Advanced Natural Language Solutions. New York: Springer,2013. 
SCHOR, J. Nascidos Para Comprar. Tradução: Eliosa Helena de Souza Cabral. São Paulo: Gente,2009

VECCHIO,Gene. The Blockbuster Toy! How to Invent the Next Big Thing. Louisiana: Pelican, 2003. 